\title{
Towards an Integration of Models of Discrimination of Immigrants: from Ultimate (Functional) to Proximate (Sociofunctional) Explanations
}

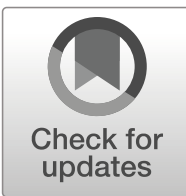

\author{
Dmitry Grigoryev $^{1}$ - Anastasia Batkhina ${ }^{1}$ (D) - Fons van de Vijver ${ }^{1,2,3,4}$. \\ John W. Berry ${ }^{1,5}$
}

Published online: 24 May 2019

(C) The Author(s) 2019

\begin{abstract}
We integrated models of discrimination of immigrants by combining established approaches to prejudice and discrimination towards immigrants (proximate explanations) using assumptions of Evolutionary-Coalitional Theory (ultimate explanations). Based on this perspective, right-wing authoritarianism (RWA), social dominance orientation (SDO), and multicultural ideology (MCI) were considered as sociofunctional motives for attitudes towards immigrants. We examined relationships between individual differences in beliefs about the social world (dangerous worldview and competitive worldview) as more distal antecedents, and RWA, SDO, and MCI as more proximal antecedents, and the endorsement of discrimination of immigrants in the socioeconomic domain by Russian majority group members as the outcome. Data were collected among 576 participants from 33 regions in Russia, using online social media. MCI predicted endorsement of discrimination of immigrants by Russian majority group members better than did RWA and SDO. SDO predicted only economic aspects of the endorsement of discrimination. The results are discussed within the Russian context, with its ethnically diverse composition of the population and high migration rates.
\end{abstract}

Keywords Multicultural ideology · Right-wing authoritarianism · Social dominance orientation · Social worldviews · Endorsement of discrimination of immigrants ·

Evolutionary-coalitional theory

From the time of the publication of Gordon Allport's (1954) seminal book, The Nature of Prejudice, psychologists have expressed strong interest in understanding intergroup

Electronic supplementary material The online version of this article (https://doi.org/10.1007/s12134-01900677-w) contains supplementary material, which is available to authorized users.

Anastasia Batkhina

batkhina.anastasia@gmail.com

Extended author information available on the last page of the article 
bias such as prejudice and discrimination. Since that time, approaches to their understanding have also significantly broadened (Dovidio et al. 2010). However, as stated by Ward et al. (2017, p. 427), "acculturation and intergroup relations can no longer be studied in isolation. Rather, these areas of research should be viewed as complementary to each other, and our theorizing concerning prejudice against immigrants in multicultural societies needs to expand to accommodate both of these research streams." A project that combined the acculturation and intercultural relations perspectives with immigrant and national samples in 17 societies found substantial empirical links between these two sets of phenomena (Berry 2017).

The present study is based on two types of explanation of prejudice and discrimination towards immigrants: ultimate explanations, represented by EvolutionaryCoalitional Theory (Sinn and Hayes 2017), and proximate explanations, which refer to established psychological approaches that have been proposed in political psychology, psychology of acculturation, and social psychology. We employ the Dual Process Model (Duckitt 2001; Duckitt and Sibley 2017) and models of multiculturalism (Berry 2006; Berry and Kalin 1995; Schalk-Soekar and van de Vijver 2008). These models have both been shown to predict prejudice and discrimination. However, it is unclear how much variation the models share and to what extent each model adds a unique component to the prediction of prejudice and discrimination. Thus, by comparing these approaches, we can extend our knowledge about prejudice and discrimination (and possibly interventions to curb them). Since we conducted our study in the Russian Federation where these processes have not been extensively studied, this research may provide additional information about the role of context. Finally, by considering ultimate explanations, we can provide an integrative perspective of both of these research streams.

\section{Context of the Study}

\section{The Common Problem of Discrimination of Immigrants in the Socioeconomic Domain}

Due to the increase of immigration flows around the world, discrimination of immigrants becomes more evident and salient (Dancygier and Laitin 2014; Polavieja 2016). Discrimination presents a formidable obstacle to the successful integration of immigrants and their children into the host society. There is much evidence that discrimination has a negative effect both on immigrant well-being and on the social and economic state of the host society (Berry and Hou 2017; Berry and Sabatier 2010; Hanson 2009). In the acculturation and intergroup relations literature, in contrast to discrimination in the cultural domain, discrimination in the socioeconomic domain has received less attention, even though according to the OECD (2016), the major concern is discrimination in the socioeconomic domain, such as job recruitment and rental housing. For example, immigrants in Western European countries are twice as likely to be unemployed than local people, and have lower wages (Algan et al. 2010). As migration to developed countries will probably increase in the coming years, economic discrimination against immigrants can evolve into a grave long-term problem requiring a comprehensive solution. The challenges for societies receiving immigrants, such as 
problems in economic integration, have negative consequences for social cohesion. They reduce immigrants' investments in their own education and professional qualifications, which, subsequently, lead to significant economic losses for the host country (Crepaz 2008; Dancygier and Laitin 2014). The inability of immigrants to spend resources on their own education and professional training (or receive sponsoring), along with the alienation and distrust they experience towards the host society can lead immigrants to perform low-skilled jobs or become unemployed (OECD 2013). This condition of immigrants enhances the negative attitudes of the host population and serves in a sense as self-fulfilling prophecy.

Most studies of discrimination of immigrants in the labor market include recruitment, career growth, and remuneration (e.g., Constant and Massey 2005; Malhotra et al. 2013). Discrimination of immigrants in recruitment is usually easier to identify than discrimination in existing labor relations. In the literature, two leading theoretical approaches to explaining the discrimination of immigrants in the labor market have been discussed: taste-based and statistical. According to Becker (1957), taste-based discrimination occurs when an employer faces (or suspects to face) negative consequences of employing immigrants. In the future, this employer will avoid taking on minorities, even if this involves certain financial costs. In contrast to this, Arrow (1973) argues that discrimination is not a taste-based, but a rational employer's decision based on stereotypes. Statistical discrimination takes its part in case there is a lack of information about a potential candidate when an employer relies on an available stereotype about an average representative of this group. Since cultural identity is a sufficiently expressive sign, the employer is more likely to rely on it. Statistical discrimination is also associated with the fact that immigrants do not have the opportunity to invest in their education, and, on average, look like less skilled workers in the eyes of employers (Adida et al. 2014).

In addition to the discrimination in the labor market, there is evidence that immigrants are discriminated against in the housing market (when renting) and in the credit (loan) market, being forced to pay higher interest rates. Some studies indicate that socioeconomic discrimination of immigrants leads to a deterioration in their well-being: increased stress, depression, and a higher frequency of cardiovascular diseases (Krieger et al. 2005; Williams and Mohammed 2009). Most studies connect the economic discrimination of immigrants to those perceived threats that are shared by the host population (Hainmueller and Hiscox 2010; Scheve and Slaughter 2001). For example, Dancygier and Donnelly (2013) showed that negative attitudes towards immigrants are increasing only when the following two conditions are met: the number of immigrants engaged in the labor market is increasing, and the economic situation in the country is deteriorating. According to the logic of the theory of economic self-interest, the threats to be presented by immigrants are perceived in two ways: (1) immigrants can claim jobs (economic competition); (2) immigrants impose a burden on the state budget (Hanson 2009).

\section{Attitudes Towards Immigrants in Russia}

In this study, we examined these topics in the Russian population, given its understudied population that is highly diverse (e.g., Fleischmann et al. 2011; Jurcik et al. 2013). The Russian population comprises more than 190 ethnic groups and the 
United Nations estimated the Russian Federation as the world's second-leading country in the number of immigrants for 2013 (Lebedeva et al. 2016). According to the Data of the Main Directorate on the Issues of Migration of the Ministry of Internal Affairs of Russia for 2017, the largest number of immigrants came from Uzbekistan, Tajikistan, Ukraine, China, Kyrgyzstan, Armenia, Azerbaijan, Kazakhstan, and Moldova (more than 500,000 people from each region). In the territory of Russia in recent years, there were between 9.2 and 11.8 million foreign citizens and individuals without citizenship. However, the education, qualifications, and professional knowledge of immigrants are often not in demand on the Russian labor market. As a result, their typical labor trajectory involves downward mobility (a vacancy that is worse than they previously held at home) and the problem of informal employment and overexploitation (including forced labor) of labor immigrants also remains (Mukomel 2017).

Intergroup relations and acculturation in Russia have been investigated within the framework of Mutual Intercultural Relations In Plural Societies project (MIRIPS; Berry 2017). Lebedeva et al. (2017) noted that despite the fact that most of the migrants come to Russia from former Soviet republics, the term "migrants" is connected mostly with im/migrants from Central Asia and the Caucasus, who are often considered as "strangers" and a source of economic burden and cultural threat. The attitudes of ethnic Russians towards migration and migrants are rather negative in spite of some mainly obvious economic need for labor migrants (Lebedeva et al. 2017). While Russia accepts immigrants not only from Central Asia and the Caucasus, some discordance between perceived and desired acculturation attitudes by immigrants is often expressed by the Russian host-group members; this discordance can elicit intergroup bias (Grigoryev et al. 2018). Moreover, there is still a lack of clear immigration policies in Russia or any special programs for enhancing the mutual intercultural relations of majority and minority groups, which could also focus on increasing of cultural, economic, and physical security of Russian majority group members, since all of this is positively related to their acceptance of immigrants and accommodation to the new polycultural realities of Russian cities (Lebedeva and Tatarko 2013).

\section{Theoretical Framework}

\section{Ultimate (Functional) and Proximate (Sociofunctional) Explanations}

The evolutionary core of intergroup relations is a cognitive mechanism that evolved to detect coalitional alliances via the categorization of the social world into "Us" versus "Them"; this is what ultimately predisposes humans to discriminate in favor of their ingroup and against the outgroup. For the human mind, ethnicity, cultural group, or race is simply one historically contingent subtype of coalition because through a long human story, they have been an ecologically valid predictor of people's social alliances and coalitional affiliations (Kurzban et al. 2001). The Evolutionary-Coalitional Theory poses three specific accommodations to coalitional competition in the ancestral environment: (a) authoritarian ("binding" orientation in the ingroup to deal with external threat and outgroup antagonism); (b) dominating (a preference for hierarchical relations between groups in order to provide hierarchically/power-based exploitation of weaker groups and individuals); and (c) universalizing (breaking coalitions and hierarchies in 
the ingroup and dealing with the threat in an individualized manner, by developing a weaker link with the ingroup and a stronger identification with broader categories such as humankind, and also sacrifices for common good) functional motives (Sinn and Hayes 2017).

Sinn and Hayes $(2017,2018)$ demonstrated a parallel between authoritarian and dominating functional motives and the in this view proximate (sociofunctional) psychological concepts as right-wing authoritarianism (RWA) and social dominance orientation (SDO), respectively. RWA is then expressing (or maintaining) motivational goals (or values) of collective (or ingroup) security and cohesion, and SDO is expressing (or maintaining) motivational goals (or values) of group dominance and superiority over others (Duckitt and Sibley 2010, 2017) that reflect a functional strategy for power-based exploitation (Sinn and Hayes 2017). Similarly, Duckitt and Sibley (2017) noted that there are different kinds of ethnocentric bias: "intragroup ethnocentric bias" (favoring the ingroup over individual group members, e.g., RWA) and "intergroup ethnocentric bias" (with an emphasis on ingroup superiority over outgroups, e.g., SDO).

In this line of reasoning, we argue the concept of multicultural ideology (MCI; Berry et al. 1977; Berry and Kalin 1995; Schalk-Soekar and van de Vijver 2008), which is frequently studied in the acculturation literature (see Berry 2006, 2016), can reflect the universalizing functional motive. Multicultural ideology (Berry et al. 1977; Berry and Kalin 1995; SchalkSoekar and van de Vijver 2008) is much wider than simple pro-diversity beliefs. Along with RWA and SDO, MCI is an ideological attitude (i.e., all three are at the same conceptual level). MCI, as a concept, attempts to encompass the general and fundamental view that cultural diversity is good for a society and for its individual members (i.e., there is a high value placed on cultural maintenance by immigrants, which is the cultural component of the multicultural policy). Furthermore, such diversity should be shared and accommodated in an equitable way (i.e., there is a high value on contact and participation, which is the social component of the policy), expressing a willingness to change one's cultural ways in order to accommodate those of other groups (Berry 2006). ${ }^{1}$ The universalizing functional motive is the opposite of the dominating functional motive (Sinn and Hayes 2017). According to Social Dominance Theory (Sidanius and Pratto 2001), society can be strengthened or weakened by personal and normative support of legitimizing myths of two different functional types: hierarchy-enhancing (promotes social inequality) and hierarchyattenuating (promotes social equality). MCI is often considered as the hierarchyattenuating myth, i.e., the consequence of low-SDO (e.g., Guimond et al. 2013; Leong 2008; Levin et al. 2012; Pelletier-Dumas et al. 2017; Sidanius and Pratto 2001; Ward and Masgoret 2006). It is important to note that the described view considers SDO as a personality trait; however, we follow Duckitt and Sibley (2010) here and argue that this is also an ideological attitude, like RWA and MCI.

The relationship between SDO, RWA, and intergroup bias is well studied. An early study in Canada found high correlations among MCI, authoritarianism, and ethnocentrism (Berry et al. 1977). However, only recently have intercultural ideologies been examined more extensively in relation to SDO and RWA (Levin et al. 2012; Rosenthal

\footnotetext{
${ }^{1}$ It is necessary to note here that is important understanding what is meant in the literature by multiculturalism (conceptualization) and how it was measured (operationalization), e.g., some measures had only about $27 \%$ common variance (see Rosenthal and Levy 2012). Different conceptualizations, operationalizations, and levels of analysis can complicate the interpretation of findings.
} 
and Levy 2012). While each of these concepts touches on the acceptance of diversity, egalitarianism, and the willingness to engage in intercultural contact (Duckitt and Sibley 2007; Ho et al. 2015; Levin et al. 2012; Pedersen et al. 2015; Rosenthal and Levy 2012), their roles may differ in contributions to an endorsement of discrimination and prejudice of immigrants due to essentially different ultimate (functional) goals evolutionary underlying them, as explained below.

\section{RWA, SDO, and $\mathrm{MCl}$ and Attitude Towards Immigrants}

Duckitt and Sibley (2010) claimed that individuals with high RWA are expected to be particularly negative towards outgroups as the latter threaten the prevailing social order, while high-SDO individuals will be negative towards competitive and low-status groups. So, the negative attitudes towards immigrants are often explained by referring to their low status, "visible" features to detect them as an outgroup, combined with an ethnocentric tendency to perceive cultural norms and practices of immigrants as wrong or threatening a deep-seated social order (Oyamot et al. 2012). Whereas high-RWA individuals tend to view immigrants as deviating from the established social order and from existing values concerning the uniform functioning of society, or as a threat to collective security (Cohrs and Stelzl 2010), high-SDO individuals tend to view immigrants as a subordinate group that can be exploited (Sinn and Hayes 2018) and a group competing for the same resources due to their zero-sum competition beliefs (Esses et al. 2001). Also, a multicultural policy can be perceived as a threat to cultural traditions and values by high-RWA individuals (Kauff et al. 2013) and ethnic diversity poses a threat to them, as it indicates non-conformism to group norms and a threat to group conformity (Asbrock and Kauff 2015; Grigoryev et al. 2018; van Assche et al. 2014).

Rosenthal and Levy (2012) found a negative relationship between universal-diverse orientation (referring to an interest in and appreciation of diversity, and being comfortable with differences) and RWA, and SDO and positive relationship with MCI. However, whereas RWA and SDO are positively associated (Perry et al. 2013), not all studies reported the stable relationship between MCI and RWA or SDO that varied from zero to negative (e.g., Berry et al. 1977; Guimond et al. 2013; Pelletier-Dumas et al. 2017; Perry et al. 2015; Rosenthal and Levy 2012). Some explanations attribute this to the influence of the social context on the above-mentioned relationship (Cohrs and Stelzl 2010; Vorauer and Sasaki 2011). For example, in a study of 23 European countries, it was found that the negative relationship between RWA and multiculturalism depends on the country's migration policy, i.e., the more liberal the policy is - the more firmly this connection is established (Kauff et al. 2013). Moreover, this relationship may be weakened or completely destroyed by the high density of immigrant population, accompanied by a high level of perceived threats (Cohrs and Stelzl 2010).

RWA was positively associated with assimilation or segregation expectations and negatively with integration acculturation expectations (Funke 2005; Perry et al. 2015; Stellmacher and Petzel 2005) and high-RWA individuals favor punishing immigrants refusing to fully assimilate and "dissolve" in the host society, while high-SDO individuals instead favor punishing those seeking this (Thomsen et al. 2008). At the same time, the main expectation for MCI is integration, which combines both cultural maintenance and participation in the larger society (Berry 2006, 2016). The sociofunctional approach can also offer an explanation of these findings. RWA 
corresponds to an elimination-exclusion reaction to remove threats (i.e., assimilation/ segregation), SDO corresponds to exploitation-exclusion reaction to exploit outgroups (i.e., segregation/marginalizing), and MCI corresponds to equity-inclusion reaction for common good (i.e., integration).

\section{Social Worldviews and Attitude Towards Immigrants}

Natural ecology, such as economic resources (Berry 1976, 2017), climate (van de Vliert 2011), and parasite-stress (Fincher and Thornhill 2012) are known to be associated with functional accommodations, including psychological dispositions. Similarly, social ecology may regulate sociofunctional accommodations, including social structures. Since people live in the social world, their social cognitive framework (i.e., perception and interpretation of social ecology) can be a driver of motivational goals expressing and maintaining ideological attitudes. How immigration is perceived is highly relevant for attitudes towards immigration (Fasel et al. 2013; Karreth et al. 2015; Sibley et al. 2013; van Assche et al. 2016). Immigrants are often perceived as an economic threat, competitors, or as the cause of an increase in crime (e.g., Fitzgerald et al. 2012; Simon and Sikich 2007). Some researchers addressed threat perception issues (e.g., Cea D'Ancona 2018; Fasel et al. 2013; Ward and Masgoret 2006). However, we follow another line of reasoning. Perceptions of specific situations guide particular behavior, but expectancies of the "general situation" (i.e., how is life in general here?) may also shed light on a characteristic response; in this sense, individual differences in expectancies about the social environment may be conceptualized as a generalized situation that provides guidance to individual reactions (Chen et al. 2016).

Duckitt (2001) proposed a Dual Process Model, with two general representations of the social world which he views as consistent social beliefs containing a relatively stable interpretation or representation of the social world and of other people in this world ("general situation"). These are the result of individual differences, individual experience of socialization, and the impact of a particular real social environment. These views are beliefs in the social world as follows: (1) dangerous and threatening ("dangerous worldview") and (2) competitive and fierce ("competitive worldview"). These are the result of individual differences, individual experience of socialization, and the impact of a particular real social environment. In this Dual Process Model, these social worldviews consider RWA and SDO respectively as antecedents (Duckitt 2001; Duckitt and Sibley 2010, 2017). Sibley et al. (2013) demonstrated that regional levels of deprivation and immigrant density were not associated with attitudes towards immigration in their own right; they interacted with these social worldviews to shape how participants felt about local-area immigration. Thus, individual differences in social worldviews can create a general predisposition for the activation of sociofunctional motives and reaction towards immigrants. In this logic, having a negative view of the social world would be inversely related to views on universalism and MCI.

\section{Present Study}

In this study we sought to cover three sociofunctional motives underlying ideological attitudes that are presumably relevant for understanding discrimination: (1) motivation 
to collective security and cohesion and resistance to social changes, possibly related to migration, through the tendency to follow the old-fashioned ways and exclusion or punishment of immigrants (RWA); (2) preferences for a hierarchical structure of society, division into the dominant and subordinate immigrant group, and the preservation of the status quo for power-based exploitation them (SDO); and (3) attitudes towards cultural diversity involving the equitable coexistence of ethnic groups within one society, the acceptability and celebrating of cultural pluralism, and a sacrifice of the status of the dominant cultural group for common good (MCI).

Russia has a high power distance; status roles and symbols are important in society (Hofstede 2001). Also, historically established ethnic hierarchies remain typical for post-Soviet Russia (Hagendoorn et al. 1998). Endorsement of inequality between immigrants and a dominant group in Russia may be based on perceived superiority of social class due to a difference in level of education, income, and social origin (SDO dimension) or/and superiority of the dominant culture, which amounts to ethnocentrism (MCI dimension). However, non-dominant cultures are supported by the Russian legal system such as the notion of minority rights in ethnic republics within the Russian Federation (Fleischmann et al. 2011). According to McFarland et al. (1992), authoritarianism among Russians is expressed as loyalty to cultural norms, which is coupled with hostility directed towards those deviating from the culture and with support for the use of force against those who are perceived as threats to the accepted order. Also, in Russia, multicultural ideology is mainly associated with tolerance and the expectation of integration for immigrants (Lebedeva et al. 2016). However, the isolation agenda is quite popular in Russia. According to a representative survey of the Levada Center among all residents of Russia in $2017,56 \%$ of the population supported residence limits in Russia for specific ethnic groups (people from the Caucasus or from the former soviet Central Asian republics or Chinese) and 58\% favored limits on the flow of migrant workers (Mukomel 2017). So, we expected a common hostile intention to exclude immigrants, to motivate them to leave the country, or since they are already here also to exploit them. Therefore, in general, we assume that RWA and SDO have a positive relationship with endorsement of discrimination of immigrants in the socioeconomic domain and a negative relationship with MCI (H1). However, taking into account different sociofunctional characters of ideological attitudes, we expected a different pattern of endorsement of discrimination of immigrants in the social (i.e., housing, school, social assistance) and economic domain (work, wages, career) separately. More specifically, we expected social specificity for RWA and economic specificity for SDO (H2).

We argue that these ideological antecedents of endorsement of discrimination of immigrants in the socioeconomic domain could be elicited by two related constructs that are broad in scope and do not only deal with ethnic groups; these ideological antecedents are based the perception of the "general situation". In our view, these antecedents constitute predictors of the main outcomes of the study; in addition, these (distal) antecedents also predict attitudes towards immigrants in their own right (Sibley et al. 2013), namely dangerous worldview and competitive worldview. Moreover, these links between distal predictors and outcomes should weaken or disappear when included in the analysis of the more closely related dimensions: RWA, SDO, and MCI. Using hierarchical regression analysis, we examined our assumption that social worldviews explain 
the variation of endorsement of discrimination in the logic of the previous paragraph at the initial step (H3), but that RWA, SDO, and MCI (as more proximal antecedents) attenuate the link of the social worldviews and explain variance at the final step (H4). Our last hypothesis involved the link between the (distal) antecedents and MCI. As argued above, the universalizing sociofunctional motive (i.e., MCI) is the opposite of the dominating sociofunctional motive (i.e., SDO); MCI, RWA, and SDO are ideological attitudes. Therefore, we expected that social worldviews predict MCI in the same logic as RWA and SDO in the Duckitt's model (2001) (H5).

\section{Method}

\section{Participants}

The total sample of 576 participants from 33 regions of Russia included 212 women (39.6\%) and 324 men $(60.4 \%)$, aged from 15 to 79 years $(M=35.1, S D=13.4) ; 115$ participants $(21.5 \%)$ were students. The sociodemographic sample characteristics are shown in more detail in Table 1.

\section{Procedure}

The data were collected online via social media. We recruited participants using targeted, paid ads at the most popular social network in Russia, named "VK" (a platform similar to Facebook). Participants were given a questionnaire and asked to read the instructions, which included information about the main topics discussed in the study, confidentiality policy, and how to contact the researchers supervising the project.

\section{Measures}

All measures were administered in Russian. We used an adaptation of these measures by Grigoryev and van de Vijver (2018). A complete set of items is available in Table S2 in the Supplemental materials.

\section{Antecedent Variables}

Social Worldview We used a short version of Duckitt's (2001) social worldview scale, a seven-point Likert scale containing six items about dangerous worldview and six items about competitive worldview (Duckitt 2001); sample items are: "There are many dangerous people in our society who will attack someone out of pure meanness, for no reason at all" and "You know that most people are out to 'screw' you, so you have to get them first when you get the chance."

Right-Wing Authoritarianism We used a short version of RWA scale, a nine-point Likert scale containing six items (Altemeyer 1996), with sample items such as "Most bad people in this country are those who do not respect our flag, our politicians and traditions," and "In these troubled times, laws have to be enforced without mercy, 
Table 1 Sociodemographic characteristics of the sample

\begin{tabular}{|c|c|c|}
\hline & Frequency & Percentage \\
\hline \multicolumn{3}{|l|}{ Gender } \\
\hline Women & 212 & 39.6 \\
\hline Men & 324 & 60.4 \\
\hline \multicolumn{3}{|l|}{ Work status } \\
\hline Unemployed & 159 & 29.7 \\
\hline Women & 88 & 55.3 \\
\hline Men & 71 & 44.7 \\
\hline Employed & 377 & 70.3 \\
\hline Part-time job & 40 & 10.6 \\
\hline Work on several jobs & 94 & 24.9 \\
\hline \multicolumn{3}{|l|}{ Income $^{\mathrm{a}}$} \\
\hline$<15,000$ rub & 219 & 40.9 \\
\hline $15,000-40,000$ rub. & 207 & 38.6 \\
\hline $40,000-60,000$ rub. & 57 & 10.6 \\
\hline$>60,000 \mathrm{rub}$ & 53 & 9.9 \\
\hline \multicolumn{3}{|l|}{ Marital status } \\
\hline Single & 188 & 35.1 \\
\hline Married & 300 & 56.0 \\
\hline Divorced & 35 & 6.5 \\
\hline Widowed & 13 & 2.4 \\
\hline \multicolumn{3}{|l|}{ Education } \\
\hline Incomplete secondary education & 17 & 3.2 \\
\hline Secondary education & 53 & 9.9 \\
\hline Vocational education & 106 & 19.8 \\
\hline Higher education & 339 & 63.2 \\
\hline Incomplete (no degree awarded) & 86 & 16.0 \\
\hline Bachelor & 37 & 6.9 \\
\hline Specialist & 140 & 26.1 \\
\hline Master & 76 & 14.2 \\
\hline $\mathrm{PhD}$ & 21 & 3.9 \\
\hline \multicolumn{3}{|l|}{ Religion } \\
\hline None & 182 & 34.0 \\
\hline Christian Orthodox & 302 & 56.3 \\
\hline Islam & 16 & 3.0 \\
\hline Other & 36 & 6.7 \\
\hline \multicolumn{3}{|l|}{ Ethnicity } \\
\hline Russian & 480 & 89.6 \\
\hline Other (non-immigrant ethnic minority) & 56 & 10.4 \\
\hline Missing & 40 & 6.9 \\
\hline
\end{tabular}

a Conversion of currency: 10,000 rub. $\approx 175$ USD 
especially when dealing with the agitators and revolutionaries who are stirring things up."

Social Dominance Orientation We used a short version of SDO scale, a nine-point Likert scale containing six items (Ho et al. 2012), with sample items such as "It is probably a good thing that certain groups are at the top and other groups are at the bottom," and "It is unjust to try to make groups equal."

Multicultural Ideology We used a short version of MCI scale, a seven-point Likert scale containing six items (Berry and Kalin 1995), with sample items such as "A society that has a variety of ethnic and cultural groups is more able to tackle new problems as they occur," and "We should recognize that cultural and racial diversity is a fundamental characteristic of Russian society."

\section{Outcome Variable}

Endorsement of Discrimination of Immigrants in the Socioeconomic Domain We developed a seven-point Likert scale containing six items. The questionnaire contained items asking for endorsement of behaviors that reflect discrimination of immigrants on the workspace, labor market, rental housing sectors, and other domains. We focused on the relevant socioeconomic domain according to literature.

\section{Data Analysis}

Using R (R Core Team 2017), we conducted data screening including checking for outliers and missing data. We used lavaan R package (Rosseel 2012) to construct the measurement model with seven latent factors and checked the fit of that model to data applying confirmatory factor analysis (CFA). Estimation of the model and subsequent models was carried out with the use of robust statistics chi-square (Satorra-Bentler corrections-MLM estimator). We employed commonly recommended global fit measures: CFI > .90; RMSEA <.05; SRMR <.08 (Kline 2016). In addition, we checked local fit using correlations residuals and modification indices and their power approach for model fit evaluation (semTools Contributors 2016). We put information about additional procedures for reliability validity in the Supplemental materials. Finally, we tested the hierarchical regression model using lavaan R package (Rosseel 2012).

\section{Results}

\section{Preliminary Analysis}

The data contained 40 observations with missing values (partially completed questionnaire) that could not be imputed using any statistical procedures. Therefore, we kept default settings (skip all subjects with missing values) for missing values in the subsequent analysis. 


\section{Measurement Model}

Confirmatory Factor Analysis The estimated measurement model had factor loadings ranging from .464 to .851 , with an average of .708 and initially showed an acceptable global fit which did not require any modification: $\chi^{2}(573, N=541)=1264.36, p<.001$; $\mathrm{CFI}=.912$; RMSEA $[90 \% \mathrm{CI}]=.047[.044, .051]$; SRMR $=.056$. When checking the local fit, we found a misspecification of seven correlations between items, but we believe that for such a complex model it is not a serious threat to the quality of measurement. Descriptive statistics including correlations, means, and standard deviations can be found in Table 2 . We put technical details about reliability validity in the Supplemental materials.

Preliminary Analysis Overall, participants demonstrated medium levels of dangerous worldviews $(M=4.49, S D=1.54$; $\max$. score $=9)$ and RWA $(M=5.41, S D=2.17$; $\max$. score $=9)$ and a relatively high level of MCI $(M=4.97, S D=2.16$; max. score $=7)$. In contrast, the mean of competitive worldview was quite low $(M=2.63, S D=1.23)$, as was SDO $(M=3.92, S D=2.16$; max. score $=9)$. At the same moderate level, participants expressed support for endorsement of discrimination of immigrants in the socioeconomic

Table 2 Correlation matrix of latent variables, descriptive statistics, and reliability and validity indicators

\begin{tabular}{|c|c|c|c|c|c|c|c|}
\hline & 1 & 2 & 3 & 4 & 5 & 6 & 7 \\
\hline 1. Dangerous worldview & .744 & .170 & .290 & .079 & .253 & .358 & .272 \\
\hline 2. Competitive worldview & $.15^{* *}$ & .606 & .197 & .320 & .479 & .186 & .360 \\
\hline 3. RWA & $.28 * * *$ & .03 & .739 & .123 & .144 & .078 & .169 \\
\hline 4. SDO & -.06 & $.32 * * *$ & -.01 & .748 & .097 & .250 & .306 \\
\hline 5. MCI & $-.24 * * *$ & $-.47 * * *$ & .01 & $-.14^{*}$ & .704 & .653 & .656 \\
\hline $\begin{array}{l}\text { 6. Endorsement of discrimination } \\
\text { (S) }\end{array}$ & $.35 * * *$ & $.20 * *$ & $.23 * * *$ & .05 & $-.65 * * *$ & .722 & .855 \\
\hline $\begin{array}{l}\text { 7. Endorsement of discrimination } \\
\text { (E) }\end{array}$ & $.28 * * *$ & $.35 * * *$ & $.32 * * *$ & $.16^{* *}$ & $-.63 * * *$ & $-.86^{* * *}$ & .724 \\
\hline$M$ & 4.49 & 2.63 & 5.41 & 3.92 & 4.97 & 3.92 & 3.00 \\
\hline$S D$ & 1.54 & 1.23 & 2.17 & 2.16 & 1.43 & 1.79 & 1.71 \\
\hline$S E$ & .06 & .05 & .09 & .09 & .06 & .08 & .07 \\
\hline$\alpha$ & .881 & .767 & .875 & .881 & .852 & .763 & .760 \\
\hline$\omega$ & .881 & .772 & .877 & .883 & .854 & .765 & .766 \\
\hline $\mathrm{H}$ & .886 & .779 & .880 & .897 & .866 & .772 & .778 \\
\hline AVE & .554 & .367 & .546 & .559 & .495 & .522 & .524 \\
\hline MSV & .122 & .216 & .102 & .103 & .416 & .734 & .734 \\
\hline ASV & .061 & .084 & .039 & .026 & .184 & .228 & .242 \\
\hline
\end{tabular}

Square root of AVE (on diagonal and italized). Under the diagonal, correlations between latent variables above diagonal, discriminant validity indicators in form of HTMT values (Max.HTMT) are shown

$A V E$ average variance extracted, $M S V$ maximum shared variance, $A S V$ average shared variance $* * * p<.001 ; * * p<.01 ; * p<.05$ 
domain $(M=3.46, S D=1.59$; max. score $=7)$ : more in social domain $(M=3.92, S D=1.79)$ than economic domain $(M=3.00, S D=1.71)$, paired $t(540)=14.58, p<.001, d=.52$.

Table 2 summarizes the means and standard deviations and describes the correlations between latent variables. As shown in Table 2 and Table 3, the endorsement of discrimination of immigrants was significantly associated with each variable, except for SDO and endorsement of discrimination in the social domain (the strongest link was with MCI). Dangerous worldview was associated with RWA and competitive worldview was associated with SDO, whereas SDO and RWA were not related to each other. In addition, there was no significant relationship between MCI and RWA. Moreover, MCI was predicted by dangerous worldview $(B[95 \% \mathrm{CI}]=-.18[-.11,-.27] ; \beta=$ $-.19, p<.001)$ and competitive worldview $(B[95 \% \mathrm{CI}]=-.42[-.52,-.31] ; \beta=$ $-.35, p<.001)$ but not by RWA $(B[95 \% \mathrm{CI}]=.03[-.03, .08] ; \beta=.04, p=.308)$ and $\operatorname{SDO}(B[95 \% \mathrm{CI}]=.03[-.09, .03] ; \beta=-.04, p=.356), R^{2}=.18($ H2, H5).

Hierarchical Regression Analysis We conducted two hierarchical regression analyses in three steps for each outcome. The multicollinearity diagnostics showed an acceptable variance inflation factor for each predictor $(\mathrm{VIF}<10)$, with VIF values ranging from 1.014 to 1.722 (overall mean of 1.238). The results of the analyses are presented in Table 4. At step 1, we entered the sociodemographic predictors: age, gender, ethnicity, affiliation to religion, education, income, work, and student status. These variables explained only 4 and $4 \%$ of the variance. Dangerous and competitive worldviews were included in the next step. Both predictors were positively and significantly associated with endorsement of discrimination of immigrants and explained an additional $9 \%$ for social and $11 \%$ for economic domain (H3). In the full model, we added SDO, RWA, and $\mathrm{MCI}$, which all had significant relations (in the expected directions) with endorsement of discrimination, except SDO and endorsement of discrimination in the social domain (H1, H2). Moreover, dangerous worldview predicted only the social domain and competitive worldview only the economic domain (H3). A comparison of the

Table 3 Correlation between the variables and each domain of endorsement of discrimination of immigrants

\begin{tabular}{|c|c|c|c|c|c|c|}
\hline & \multirow[t]{2}{*}{$M(S D)$} & \multicolumn{5}{|c|}{ Antecedents } \\
\hline & & DW & $\mathrm{CW}$ & RWA & SDO & MCI \\
\hline \multicolumn{7}{|l|}{ Social domain } \\
\hline Housing & $3.63(2.15)$ & $.22 * * *$ & $.10 *$ & $.19 * * *$ & .07 & $-.46^{* * *}$ \\
\hline Social assistance & $4.71(2.14)$ & $.28 * * *$ & $.08 *$ & $.24 * * *$ & .02 & $-.35^{* * * *}$ \\
\hline School & $3.41(2.23)$ & $.23 * * *$ & $.16^{* * *}$ & $.08 *$ & .02 & $-.50 * * *$ \\
\hline \multicolumn{7}{|l|}{ Economic domain } \\
\hline Wages & $3.30(2.23)$ & $.18^{* * * *}$ & $.24 * * *$ & $.24 * * *$ & $.12 * *$ & $-.39 * * *$ \\
\hline Premiums & $2.55(1.93)$ & $.16^{* * * *}$ & $.24 * * *$ & $.10 * *$ & $.11 * *$ & $-.47 * * *$ \\
\hline Career & $3.16(2.08)$ & $.21 * * *$ & $.20 * * *$ & $.28 * * *$ & $.11 * *$ & $-.44 * * *$ \\
\hline
\end{tabular}

We recoded reversed items in one direction so that endorsement of discrimination in the domain would mean a high score on the scale

$D W$ dangerous worldview, $C W$ competitive worldview, $R W A$ right-wing authoritarianism, $S D O$ social dominance orientation, $M C I$ multicultural ideology 


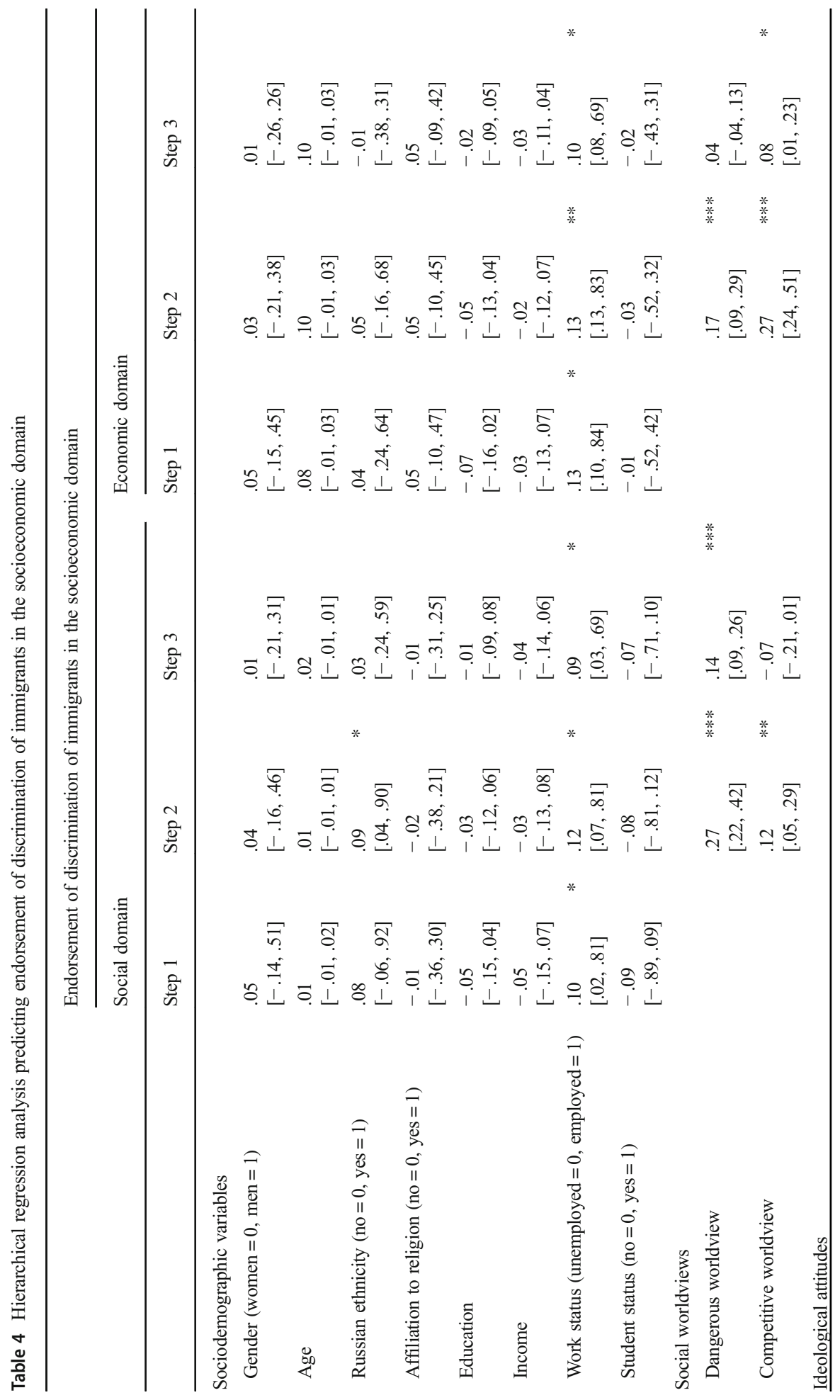




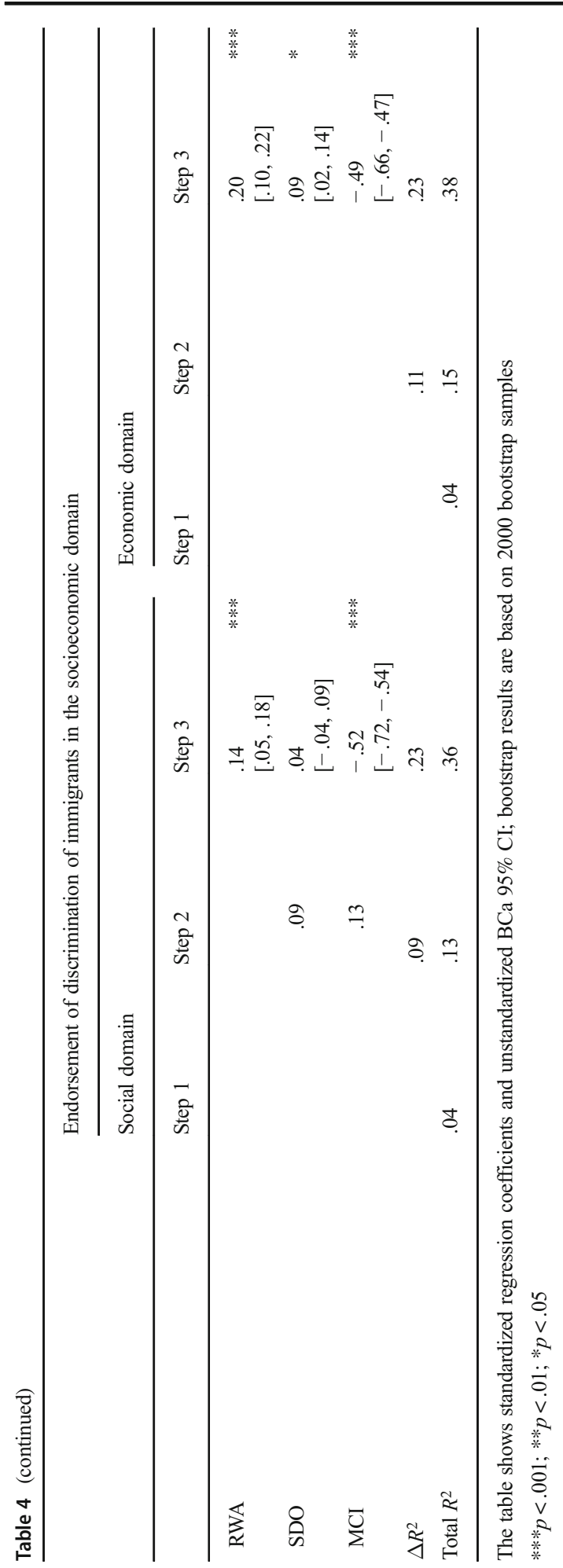


effect sizes showed that MCI showed the strongest contribution to explaining endorsement of the discrimination. The common explained variance of endorsement of discrimination was 36 and 38\%. The last set of predictors (RWA, SDO, and MCI) could explain much more (23 and 23\%) than the social worldviews (9 and 11\%) (H4).

\section{Discussion}

We set out to offer an integrated explanation of attitudes towards immigrants based on sociofunctional approach and so examine the role of social worldviews, SDO, RWA, and MCI in the explanation of endorsement of discrimination of immigrants by the Russian majority group members. Our hypotheses about the role of the antecedents were supported. Indeed, RWA, SDO, and MCI contributed to the endorsement of discrimination in both social and economic domains by their own sociofunctional manner. RWA improved the endorsement of discrimination in both domains. We attribute this to the fact that one of the RWA's motivational goals is to exclude and punish those groups that present a threat to cultural norms and the cohesion of the host society. As mentioned above, the level of perception of immigrants as a threat is quite high among the host population in Russia. Thus, both social and economic domains of discrimination can be perceived by individuals with high RWA, as an opportunity, firstly, to "punish" immigrants, and, secondly, to show them that they are "unwanted guests" in Russia and force them to leave the country, thereby excluding them from of the society. The weak link between SDO and endorsement of discrimination of immigrants in the economic domain, we assume that the motivational goal of exploitation of immigrants, which is associated with SDO in a sociofunctional approach, may be less associated with socioeconomic discrimination as opposed to the motives of punishment and exclusion (RWA). The role of social worldviews weakened when RWA and SDO were included but at the same time, it remained significant for dangerous worldview and endorsement of discrimination in the social domain and for competitive worldview and endorsement of discrimination in the economic domain. Thus, as we expected, the perception of the "general situation" plays a role in the discrimination of migrants in their own right as argued by Sibley et al. (2013). While the perception of the world as dangerous stimulates the elimination of any threatening element and social discrimination, the perception of the world as competitive stimulates the elimination of competing groups, and since immigrants are perceived by competitors primarily in the labor market, discrimination mainly involves the economic sphere. These findings are in line with the "multiculturalism hypothesis" (Berry 2006, 2017), which proposes that only when people feel secure and confident in their place in society will they be able to accept "others" who are living among them. Conversely, when people feel that they are threatened, or that their place is being undermined, they will have hostile attitudes and behaviors towards "others". These findings, both internationally (Berry 2017) and previously in Russia (Lebedeva et al. 2016), have led to recommendations for improving intergroup relations in Russia. These authors pointed to the need for (1) the promotion of a policy of multiculturalism and integration; (2) increasing the level of cultural, economic, and personal security; and (3) providing opportunities for intercultural contact. 
The key relationships between the main components of the Dual Process Model (Duckitt 2001; Duckitt and Sibley 2017) were supported, with the exception of the relationship between RWA and SDO. The lack of a significant correlation between RWA and SDO was somewhat at odds with the value of about +.30 , found in a metaanalysis (see Perry et al. 2013). These null findings may be measurement artifact or/and specific for modern Russia. The relationship between RWA and SDO is probably due to a positive association between their specific components: authoritarian aggression and SDO-dominance (Kandler et al. 2016). The short versions of the measures we employed may have had an insufficient number of overlapping items, although the used Altemeyer's measure (1996) covered some authoritarian aggression and the SDO measure included dominance items. However, there is another explanation possible. The results are in line with previous studies in other East or Central European countries (Duriez et al. 2005). Individuals supporting RWA tend to support only those norms and values which are considered conservative in their culture. However, social norms that regulate hierarchical relations, justice, social cohesion, or distribution of power could be different across countries and may be quite specific for Russia. For example, a distributive justice norm as equality was positively associated with RWA among Russians and negatively associated among Americans whereas laissez-faire individualism showed the opposite pattern (McFarland et al. 1992) and RWA was positively correlated with support for egalitarianism and communist distributive justice later (McFarland et al. 1996). These associations may go back to the Soviet past (Šram and Dulić 2015); the Soviet ideology formally proclaimed all groups to be equal and supported internationalism. On the other hand, the associations we found may refer more to another aspect of the Russian society. Inequality of cultural groups and inequality of social groups may have different meanings in the Russian context, with the latter being more viewed as a historical, immutable reality. Early studies have shown some influence of the Soviet legacy on RWA; authoritarianism was tied to conventionalism rather than to the specific conservative ideologies found in the West (see McFarland et al. 1992, 1993, 1996; see also Hadarics 2017, about post-socialist Central Eastern Europe), but little is known about the state of affairs in modern Russia.

\section{Limitations and Further Research}

The use of multilevel models and cross-cultural comparisons would be an interesting extension of the logic of our model. Cohrs and Stelzl (2010) considered the interplay of individual and sociocultural factors and reported that RWA was a particularly strong predictor of anti-immigrant attitudes in countries where immigrants were perceived as increasing the crime rate and as not being beneficial to the economy (e.g., Germany and Italy); and SDO was a stronger predictor in countries with a higher relative unemployment rate of immigrants (e.g., Belgium and Sweden). Economic development and emancipation values could be such moderators of MCI because they refer to a universalizing sociofunctional motive. Thus, we need to consider such countryspecific moderators in our models of attitudes vis-à-vis intergroup contact and its antecedents. The development of our model can be seen as a promising step towards explaining the positive and negative attitudes towards ethnic minorities and various aspects of migration in general. 
It would thus be valuable to take into account the specificity of each particular group of immigrants and their particular adaptation experience, rather than consider some "abstract," decontextualized group of immigrants as outgroup. Satherley and Sibley (2016) noted that the extent to which RWA and SDO are associated with attitudes towards immigrant groups is likely to differ depending on the specific group examined, and considering attitudes towards immigrants in general is likely to hide some important details. So, we may expect not only domain specificity, as in our study (social vs. economic), but also group specificity; the combination of both perspectives could strengthen our model.

Sinn and Hayes $(2017,2018)$ associate the universalizing sociofunctional motive with universalism of Schwartz' basic human values in one level with RWA and SDO, while we associate it with MCI. The conceptual level of values (i.e., individual accommodations) and ideological attitudes (i.e., coalitional accommodations) is different. We believe that future research could consider values and social worldviews as antecedents of the ideological attitudes since this is more consistent with the logic of the nomological network.

We followed Altemeyer (1996) and measured RWA as a unidimensional construct conceptually, inclusive three components: authoritarian aggression, authoritarian submission, and conventionalism. However, some evidence has been presented for a tripartite approach to RWA: (aggression/authoritarianism, submission/conservatism, and conventionalism/traditionalism; e.g., Dunwoody and Funke 2016; Duckitt et al. 2010; Funke 2005), and for two dimensions of SDO (dominance and (anti-)egalitarianism; e.g., Ho et al. 2012, 2015). Future research could clarify the sociofunctional aspects of each of them.

Finally, our model dealt with individual differences in ideological attitudes and "general situation" (i.e., non-dynamic constant settings: perception of environment as dangerous and competitive) and did not describe the effects of different situational factors that may also matter. Both approaches have their own purpose: models of individual differences can explain why some people are more prone to show intergroup bias, whereas models of situational factors can explain why some dynamic contexts cause massive and relatively homogeneous behavior changes (Hodson and Dhont 2015). Future studies could gain in explanatory power by combining models of individual and situational variation.

\section{Implications}

We wish to emphasize that the strongest negative oriented association with the discrimination of immigrants in the economic context is established by MCI, which provides an opportunity for intervention at the policy and program level. There is reason to believe that a nationwide implementation of multicultural politics could lead to the reduction of prejudices and discrimination (Berry 2006, 2016; Duckitt 2001; Koopmans 2013). It is important to start the policy of multiculturalism from a careful analysis of prevailing attitudes in society (see Berry 2006, 2016). Multicultural policies in the context of a widespread prevalence of authoritarian and hierarchical representations and attitudes (i.e., in the case of activated authoritarian and dominating sociofunctional motives) may be unsuccessful and even sometimes produce a negative effect (e.g., Kauff et al. 2013; van Assche et al. 2018; Vorauer and Sasaki 2011). In the society where the lack of feelings of safety and social control among individuals with a conservative orientation may enhance 
negative views on diversity and strict boundaries between the ingroup and outgroup (see, e.g., Crawford 2017; Jost et al. 2003; Napier et al. 2017) (i.e., in the case of activated the authoritarian sociofunctional motive). The hypothesis of ideological asymmetry proposed in Social Dominance Theory poses that multiculturalism is more beneficial for immigrants than for the majority group; multiculturalism allows immigrants to maintain their own culture and obtain a higher social status in the society, while the majority group can perceive immigrants and their desire to preserve their culture as a threat to their own status and resources (Schalk-Soekar and van de Vijver 2008) (i.e., in the case of activated the dominating sociofunctional motive).

In many societies, including Russia, immigration and the plural composition of society are not necessarily related social phenomena. After all, many plural societies are not so because of immigration; they have been so for many generations, as a result of national boundaries having been drawn around culturally disparate peoples. Most societies in Africa, Asia, and the Americas (as well as Australia and New Zealand) were plural before European colonization and immigration but it is the common perception in contemporary Europe that the current level of cultural diversity is due to recent migration, despite the long-standing presence of peoples such as Basque, Catalans, Bretons, Frisians, Aostian, Tyrolians, and Sami. So, why blame diversity on immigration when so many countries have a long history of pluralism? The logic of sociofunctional accommodations approach addresses the cognitive mechanism that evolved to detect coalitional alliances via the categorization of the social world into "Us" versus "Them". These boundaries are movable and changeable. ${ }^{2}$ The activation of a universalizing functional motive (i.e., breaking coalitions and hierarchies in the ingroup and dealing with the threat in an individualized manner, by developing a weaker link with the ingroup and a stronger identification with broader categories such as humankind, and also sacrifices for common good) apparently requires a certain state of society and development of the country. The Theory of Emancipation poses that emancipative values do not guide people's actions as long as existential constraints on human life are strong, and only gain momentum when people become more capable due to improving living conditions and rising action resources (Welzel 2013). In the case of a favorable situation on the level of society and the country (i.e., sufficient resources and the lack of real threats), we are dealing with individual differences in social worldviews, which are also amenable to adjustment. Furthermore, the observation that "we have always been always plural, well before recent immigration" suggests a way forward for policy and program development.

In our view, policies that are evidence-based are more likely to be successful than those based only on pre-conceptions or political expediency. The benefits of the multicultural vision need to be articulated, and advocated widely in ways that the general public can understand and accept this vision. Particularly important is the claim that life for everyone is enriched culturally and economically in multicultural societies (Berry 1998; Berry and Sam 2013). Community mobilization is required to push (from

\footnotetext{
There is evidence that MCI does change over time (e.g., Breugelmans et al. 2009). In Canada, the multicultural vision, which espouses the dual values of cultural diversity and equitable participation, receives general and increasing support from the Canadian population (Berry 2013; Environics Institute 2015; Kymlicka 2010). In the Environics Institute study, they note that "The latest Focus Canada surveyupdating trends dating back to the 1980s" shows that Canadian attitudes about these issues (immigration and multiculturalism) has held steady or grown more positive over the past 3 to 5 years.
} 
the bottom up) towards achieving a more accepting and inclusive society. Political leadership (from the top down) is also essential. Leaders who could advocate for the multicultural way of living together have clear models to follow: the Canadian and European Union policy statements provide clear examples of these principles, which could be emulated and promoted elsewhere. The multicultural vision of (providing a secure and non-discriminatory social and cultural environment, of opportunities for equitable intercultural contact and participation, and of ways to be engaged in and identify with more than one culture) offers a clear basis for moving towards achieving a more harmonious plural society. Despite the obvious difficulties, and contentious debates in many contemporary societies, and even policies and pronouncements that are opposite to them, the findings of the present study may serve as a basis for policy development.

Funding The article was prepared within the framework of the Basic Research Program at the National Research University Higher School of Economics (HSE) and supported within the framework of a subsidy by the Russian Academic Excellence Project "5-100."

Open Access This article is distributed under the terms of the Creative Commons Attribution 4.0 International License (http://creativecommons.org/licenses/by/4.0/), which permits unrestricted use, distribution, and reproduction in any medium, provided you give appropriate credit to the original author(s) and the source, provide a link to the Creative Commons license, and indicate if changes were made.

\section{References}

Adida, C. L., Laitin, D. D., \& Valfort, M.-A. (2014). Muslims in France: identifying a discriminatory equilibrium. Journal of Population Economics, 27, 1039-1086. https://doi.org/10.1007/s00148-0140512-1.

Algan, Y., Dustmann, C., Glitz, A., \& Manning, A. (2010). The economic situation of first and secondgeneration immigrants in France, Germany and the United Kingdom. The Economic Journal, 120, F4 F30. https://doi.org/10.1111/j.1468-0297.2009.02338.x.

Allport, G. W. (1954). The nature of prejudice. Cambridge, MA: Addison-Wesley.

Altemeyer, B. (1996). The authoritarian specter. Cambridge, MA: Harvard University Press.

Arrow, K. J. (1973). The theory of discrimination. In O. Aschenfelter \& A. Rees (Eds.), Discrimination in labor markets (pp. 3-33). Princeton, NJ: Princeton University Press.

Asbrock, F., \& Kauff, M. (2015). Authoritarian disbeliefs in diversity. The Journal of Social Psychology, 155, 553-558. https://doi.org/10.1080/00224545.2015.1038497.

van Assche, J., Roets, A., Dhont, K., \& Van Hiel, A. (2014). Diversity and out-group attitudes in the Netherlands: the role of authoritarianism and social threat in the neighbourhood. Journal of Ethnic and Migration Studies, 40, 1414-1430. https://doi.org/10.1080/1369183X.2013.876895.

van Assche, J., Roets, A., Dhont, K., \& van Hiel, A. (2016). The association between actual and perceived ethnic diversity: the moderating role of authoritarianism and implications for outgroup threat, anxiety, and mistrust. European Journal of Social Psychology, 46, 807-817. https://doi.org/10.1002/ejsp.2211.

van Assche, J., Asbrock, F., Dhont, K., \& Roets, A. (2018). The diversity challenge for high and low authoritarians: multilevel and longitudinal effects through intergroup contact and threat. Personality and Social Psychology Bulletin, 44, 1163-1179. https://doi.org/10.1177/0146167218764653.

Becker, G. (1957). The economics of discrimination. Chicago, IL: University Chicago Press.

Berry, J. W. (1976). Human ecology and cognitive style. Thousand Oaks, CA: Sage.

Berry, J. W. (1998). Social psychological costs and benefits of multiculturalism. Trames: Estonian Journal of Social Sciences, 2, 209-233. 
Berry, J. W. (2006). Mutual attitudes among immigrants and ethnocultural groups in Canada. International Journal of Intercultural Relations, 30, 719-734. https://doi.org/10.1016/j.ijintrel.2006.06.004.

Berry, J. W. (2013). Research on multiculturalism in Canada. International Journal of Intercultural Relations, 37, 663-675. https://doi.org/10.1016/j.ijintrel.2013.09.005.

Berry, J. W. (2016). Diversity and equity. Cross Cultural \& Strategic Management, 23, 413-430. https://doi. org/10.1108/CCSM-03-2016-0085.

Berry, J. W. (2017). Mutual intercultural relations. Cambridge, UK: Cambridge University Press.

Berry, J. W., \& Hou, F. (2017). Acculturation, discrimination and wellbeing among second generation of immigrants in Canada. International Journal of Intercultural Relations, 61, 29-39. https://doi. org/10.1016/j.ijintrel.2017.08.003.

Berry, J. W., \& Kalin, R. (1995). Multicultural and ethnic attitudes in Canada: An overview of the 1991 National Survey. Canadian Journal of Behavioural Science, 27, 301-320. https://doi.org/10.1037/0008400X.27.3.301.

Berry, J. W., \& Sabatier, C. (2010). Acculturation, discrimination, and adaptation among second generation immigrant youth in Montreal and Paris. International Journal of Intercultural Relations, 34, 191-207. https://doi.org/10.1016/j.ijintrel.2009.11.007.

Berry, J. W., \& Sam, D. L. (2013). Accommodating cultural diversity and achieving equity: psychological dimensions of multiculturalism. European Psychologist, 18, 151-157. https://doi.org/10.1027/1016-9040 /a000167.

Berry, J. W., Kalin, R., \& Taylor, D. M. (1977). Multiculturalism and ethnic attitudes in Canada. Ottawa, Canada: Supply and Services Canada.

Breugelmans, S., van de Vijver, F., \& Schalk-Soekar, S. (2009). Stability of majority attitudes toward multiculturalism in the Netherlands between 1999 and 2007. Applied Psychology, 58, 653-671. https://doi.org/10.1111/j.1464-0597.2008.00368.x.

Cea D'Ancona, M. Á. (2018). What determines the rejection of immigrants through an integrative model. Social Science Research, 74, 1-15. https://doi.org/10.1016/j.ssresearch.2018.05.008.

Chen, S. X., Lam, B. C. P., Wu, W. C. H., Ng, J. C. K., Buchtel, E. E., Guan, Y., \& Deng, H. (2016). Do people's world views matter? The why and how. Journal of Personality and Social Psychology, 110, 743765. https://doi.org/10.1037/pspp0000061.

Cohrs, J. C., \& Stelzl, M. (2010). How ideological attitudes predict host society members' attitudes toward immigrants: exploring cross-national differences. Journal of Social Issues, 66, 673-694. https://doi. org/10.1111/j.1540-4560.2010.01670.x.

Constant, A., \& Massey, D. S. (2005). Labor market segmentation and the earnings of German guestworkers. Population Research and Policy Review, 24, 489-512. https://doi.org/10.1007/s11113-005-4675-z.

Crawford, J. T. (2017). Are conservatives more sensitive to threat than liberals? It depends on how we define threat and conservatism. Social Cognition, 35, 354-373. https://doi.org/10.1521/soco.2017.35.4.354.

Crepaz, M. (2008). Trust beyond borders: immigration, the welfare state, and identity in modern societies. Ann Arbor, MI: University Michigan Press. https://doi.org/10.3998/mpub.133495.

Dancygier, R., \& Donnelly, M. (2013). Sectoral economies, economic contexts, and attitudes toward immigration. The Journal of Politics, 75, 17-35. https://doi.org/10.1017/S0022381612000849.

Dancygier, R. M., \& Laitin, D. D. (2014). Immigration into Europe: economic discrimination, violence, and public policy. Annual Review of Political Science, 17, 43-64. https://doi.org/10.1146/annurev-polisci$082012-115925$.

Dovidio, J. F., Hewstone, M., Glick, P., \& Esses, V. M. (2010). Prejudice, stereotyping, and discrimination: theoretical and empirical overview. In J. F. Dovidio, M. Hewstone, P. Glick, \& V. M. Esses (Eds.), SAGE handbook of prejudice, stereotyping, and discrimination (pp. 3-28). London, UK: Sage.

Duckitt, J. (2001). A dual-process cognitive-motivational theory of ideology and prejudice. In Advances in Experimental Social Psychology, 33, 41-113. doi:https://doi.org/10.1016/S0065-2601(01)80004-6.

Duckitt, J., \& Sibley, C. G. (2007). Right wing authoritarianism, social dominance orientation and the dimensions of generalized prejudice. European Journal of Personality, 21, 113-130. https://doi. org/10.1002/per.614.

Duckitt, J., \& Sibley, C. G. (2010). Personality, ideology, prejudice, and politics: a dual-process motivational model. Journal of Personality, 78, 1861-1894. https://doi.org/10.1111/j.1467-6494.2010.00672.x.

Duckitt, J., \& Sibley, C. G. (2017). The dual process motivational model of ideology and prejudice. In C. G. Sibley \& F. K. Barlow (Eds.), The Cambridge handbook of the psychology of prejudice (pp. 188-221). Cambridge, UK: Cambridge University Press. https://doi.org/10.1017/9781316161579.009.

Duckitt, J., Bizumic, B., Krauss, S. W., \& Heled, E. (2010). A tripartite approach to right-wing authoritarianism: the authoritarianism-conservatism-traditionalism model. Political Psychology, 31, 685-715. https://doi.org/10.1111/j.1467-9221.2010.00781.x. 
Dunwoody, P. T., \& Funke, F. (2016). The aggression-submission-conventionalism scale: testing a new three factor measure of authoritarianism. Journal of Social and Political Psychology, 4, 571-600. https://doi. org/10.5964/jspp.v4i2.168.

Duriez, B., van Hiel, A., \& Kossowska, M. (2005). Authoritarianism and social dominance in Western and Eastern Europe: the importance of the sociopolitical context and of political interest and involvement. Political Psychology, 26, 299-320. https://doi.org/10.1111/j.1467-9221.2005.00419.x.

Environics Institute (2015). Focus Canada: Canadian public opinion about immigration and multiculturalism http://www.environicsinstitute.org/institute-projects/completed-projects/focus-canada-2015-immigrationand-multiculturalism. Accessed 04 Apr 2018.

Esses, M., Dovidio, J. F., Jackson, L. M., \& Armstrong, T. L. (2001). The immigration dilemma: the role of perceived group competition, ethnic prejudice, and national identity. Journal of Social Issues, 57, 389412. https://doi.org/10.1111/0022-4537.00220.

Fasel, N., Green, E. G. T., \& Sarrasin, O. (2013). Facing cultural diversity: anti-immigrant attitudes in Europe. European Psychologist, 18, 253-262. https://doi.org/10.1027/1016-9040/a000157.

Fincher, C. L., \& Thornhill, R. (2012). Parasite-stress promotes in-group assortative sociality: the cases of strong family ties and heightened religiosity. Behavioral and Brain Sciences, 35, 61-79. https://doi. org/10.1017/S0140525X11000021.

Fitzgerald, J., Curtis, K. A., \& Corliss, C. L. (2012). Anxious publics: worries about crime and immigration. Comparative Political Studies, 45, 477-506. https://doi.org/10.1177/0010414011421768.

Fleischmann, F., Verkuyten, M., \& Poppe, E. (2011). Ethnic and republic identification in the Russian Federation and Ukraine: a social dominance perspective. Journal of Ethnic and Migration Studies, 37, 23-41. https://doi.org/10.1080/1369183X.2011.521364.

Funke, F. (2005). The dimensionality of right-wing authoritarianism: lessons from the dilemma between theory and measurement. Political Psychology, 26, 195-218. https://doi.org/10.1111/j.14679221.2005.00415.x.

Grigoryev, D., \& van de Vijver, F. (2018). Acculturation expectation profiles of Russian majority group members and their intergroup attitudes. International Journal of Intercultural Relations, 64, 90-99. https://doi.org/10.1016/j.jintrel.2018.03.001.

Grigoryev, D., van de Vijver, F., \& Batkhina, A. (2018). Discordance of acculturation attitudes of the host population and their dealing with immigrants. Journal of Intercultural Communication Research, 47, 491-509. https://doi.org/10.1080/17475759.2018.1497678.

Guimond, S., Crisp, R. J., De Oliveira, P., Kamiejski, R., Kteily, N., Kuepper, B., et al. (2013). Diversity policy, social dominance, and intergroup relations: predicting prejudice in changing social and political contexts. Journal of Personality and Social Psychology, 104, 941-958. https://doi.org/10.1037/a0032069.

Hadarics, M. (2017). Conservation motivation, social equality and left-right ideological preferences in Western and Eastern Europe. Europe's Journal of Psychology, 13, 336-351. https://doi.org/10.5964/ejop.v13 i2.1334.

Hagendoorn, L., Drogendijk, R., Tumanov, S., \& Hraba, J. (1998). Inter-ethnic preferences and ethnic hierarchies in the former Soviet Union. International Journal of Intercultural Relations, 22, 483-503. https://doi.org/10.1016/S0147-1767(98)00020-0.

Hainmueller, J., \& Hiscox, M. J. (2010). Attitudes toward highly skilled and low-skilled immigration: evidence from a survey experiment. American Political Science Review, 104, 61-84. https://doi. org/10.1017/S0003055409990372.

Hanson, G. H. (2009). The economic consequences of the international migration of labor. Annual Review of Economics, 1, 179-207. https://doi.org/10.1146/annurev.economics.050708.143247.

Ho, A. K., Sidanius, J., Pratto, F., Levin, S., Thomsen, L., Kteily, N., \& Sheehy-Skeffington, J. (2012). Social dominance orientation: revisiting the structure and function of a variable predicting social and political attitudes. Personality and Social Psychology Bulletin, 38, 583-606. https://doi.org/10.1177 $/ 0146167211432765$.

Ho, A. K., Sidanius, J., Kteily, N., Sheehy-Skeffington, J., Pratto, F., Henkel, K. E., Foels, R., \& Stewart, A. L. (2015). The nature of social dominance orientation: theorizing and measuring preferences for intergroup inequality using the new $\mathrm{SDO}_{7}$ scale. Journal of Personality and Social Psychology, 109, 1003-1028. https://doi.org/10.1037/pspi0000033.

Hodson, G., \& Dhont, K. (2015). The person-based nature of prejudice: individual difference predictors of intergroup negativity. European Review of Social Psychology, 26, 1-42. https://doi.org/10.1080 /10463283.2015.1070018.

Hofstede, G. (2001). Culture's consequences: comparing values, behaviors, institutions, and organizations across nations (2nd ed.). Thousand Oaks, CA: Sage. 
Jost, J. T., Glaser, J., Kruglanski, A. W., \& Sulloway, F. J. (2003). Political conservatism as motivated social cognition. Psychological Bulletin, 129, 339-375. https://doi.org/10.1037/0033-2909.129.3.339.

Jurcik, T., Chentsova-Dutton, Y. E., Solopieieva-Jurcikova, I., \& Ryder, A. G. (2013). Russians in treatment: the evidence base supporting cultural adaptations: adapting treatments for Russian-speaking immigrants. Journal of Clinical Psychology, 69, 774-791. https://doi.org/10.1002/jclp.21971.

Kandler, C., Bell, E., \& Riemann, R. (2016). The structure and sources of right-wing authoritarianism and social dominance orientation. European Journal of Personality, 30, 406-420. https://doi.org/10.1002 /per.2061.

Karreth, J., Singh, S. P., \& Stojek, S. M. (2015). Explaining attitudes toward immigration: the role of regional context and individual predispositions. West European Politics, 38, 1174-1202. https://doi.org/10.1080 /01402382.2015.1022039.

Kauff, M., Asbrock, F., Thorner, S., \& Wagner, U. (2013). Side effects of multiculturalism: the interaction effect of a multicultural ideology and authoritarianism on prejudice and diversity beliefs. Personality and Social Psychology Bulletin, 39, 305-320. https://doi.org/10.1177/0146167212473160.

Kline, R. B. (2016). Principles and practice of structural equation modeling (4th ed.). New York, NY: The Guilford Press.

Koopmans, R. (2013). Multiculturalism and immigration: a contested field in cross-national comparison. Annual Review of Sociology, 39, 147-169. https://doi.org/10.1146/annurev-soc-071312-145630.

Krieger, N., Smith, K., Naishadham, D., Hartman, C., \& Barbeau, E. M. (2005). Experiences of discrimination: validity and reliability of a self-report measure for population health research on racism and health. Social Science \& Medicine, 61, 1576-1596.

Kurzban, R., Tooby, J., \& Cosmides, L. (2001). Can race be erased? Coalitional computation and social categorization. Proceedings of the National Academy of Sciences, 98, 15387-15392. https://doi. org/10.1073/pnas.251541498.

Kymlicka, W. (2010). The rise and fall of multiculturalism? New debates on inclusion and accommodation in diverse societies: The rise and fall of multiculturalism. International Social Science Journal, 61, 97-112. https://doi.org/10.1111/j.1468-2451.2010.01750.x.

Lebedeva, N., \& Tatarko, A. (2013). Multiculturalism and immigration in post-Soviet Russia. European Psychologist, 18, 169-178. https://doi.org/10.1027/1016-9040/a000161.

Lebedeva, N., Tatarko, A., \& Berry, J. W. (2016). Social and psychological basis of multiculturalism: testing of intercultural interaction hypotheses in the Russian context. Psikhologicheskii Zhurnal, 37, 92-104.

Lebedeva, N., Galyapina, V., Lepshokova, Z., \& Ryabichenko, T. (2017). Intercultural relations in Russia. In J. W. Berry (Ed.), Mutual intercultural relations (pp. 34-59). Cambridge, UK: Cambridge University Press. https://doi.org/10.1017/9781316875032.002.

Leong, C.-H. (2008). A multilevel research framework for the analyses of attitudes toward immigrants. International Journal of Intercultural Relations, 32, 115-129. https://doi.org/10.1016/j. ijintrel.2007.10.002.

Levin, S., Matthews, M., Guimond, S., Sidanius, J., Pratto, F., Kteily, N., Pitpitan, E. V., \& Dover, T. (2012). Assimilation, multiculturalism, and colorblindness: mediated and moderated relationships between social dominance orientation and prejudice. Journal of Experimental Social Psychology, 48, 207-212. https://doi.org/10.1016/j.jesp.2011.06.019.

Malhotra, N., Margalit, Y., \& Mo, C. H. (2013). Economic explanations for opposition to immigration: distinguishing between prevalence and conditional impact. American Journal of Political Science, 57, 391-410. https://doi.org/10.1111/ajps.12012.

McFarland, S. G., Ageyev, V. S., \& Abalakina-Paap, M. A. (1992). Authoritarianism in the former Soviet Union. Journal of Personality and Social Psychology, 63, 1004-1010. https://doi.org/10.1037/00223514.63.6.1004.

McFarland, S. G., Ageyev, V. S., \& Abalakina, M. (1993). The authoritarian personality in the United States and the former Soviet Union: comparative studies. In W. F. Stone, G. Lederer, \& R. Christie (Eds.), Strength and weakness (pp. 199-225). New York, NY: Springer New York. https://doi.org/10.1007/9781-4613-9180-7_10.

McFarland, S. G., Ageyev, V. S., \& Djintcharadze, N. (1996). Russian authoritarianism two years after communism. Personality and Social Psychology Bulletin, 22, 210-217. https://doi.org/10.1177 /0146167296222010.

Mukomel, V. I. (2017). Migrants at the Russian labor market: occupations, mobility, intensity of labor and wages. Statistics and Economics, (6), 69-79. https://doi.org/10.21686/2500-3925-2017-6-69-79.

Napier, J. L., Huang, J., Vonasch, A. J., \& Bargh, J. A. (2017). Superheroes for change: physical safety promotes socially (but not economically) progressive attitudes among conservatives. European Journal of Social Psychology., 48, 187-195. https://doi.org/10.1002/ejsp.2315. 
OECD (2013). OECD International Migration Database and labour market outcomes of immigrants. Retrieved from https://www.oecd.org/els/mig/keystat.htm. Accessed 21 Apr 2018.

OECD. (2016). OECD Factbook 2015-2016: economic, environmental and social statistics. Paris: OECD Publishing. https://doi.org/10.1787/factbook-2015-en.

Oyamot, C. M., Fisher, E. L., Deason, G., \& Borgida, E. (2012). Attitudes toward immigrants: the interactive role of the authoritarian predisposition, social norms, and humanitarian values. Journal of Experimental Social Psychology, 48, 97-105. https://doi.org/10.1016/j.jesp.2011.08.003.

Pedersen, A., Paradies, Y., \& Barndon, A. (2015). The consequences of intergroup ideologies and prejudice control for discrimination and harmony. Journal of Applied Social Psychology, 45, 684-696. https://doi. org/10.1111/jasp.12330.

Pelletier-Dumas, M., de la Sablonnière, R., \& Guimond, S. (2017). The role of assimilation and multiculturalism for the relation between social dominance orientation and prejudice: the case of Anglophones and Francophones in Québec. Journal of Cross-Cultural Psychology, 48, 874-891. https://doi.org/10.1177 /0022022117706414.

Perry, R., Sibley, C. G., \& Duckitt, J. (2013). Dangerous and competitive worldviews: a meta-analysis of their associations with social dominance orientation and right-wing authoritarianism. Journal of Research in Personality, 47, 116-127. https://doi.org/10.1016/j.jrp.2012.10.004.

Perry, R., Paradies, Y., \& Pedersen, A. (2015). Religious ambivalence: suppression of pro-social attitudes toward asylum seekers by right-wing authoritarianism. The International Journal for the Psychology of Religion, 25, 230-246. https://doi.org/10.1080/10508619.2014.921473.

Polavieja, J. G. (2016). Labour-market competition, recession and anti-immigrant sentiments in Europe: occupational and environmental drivers of competitive threat. Socio-Economic Review, 14, 395-417. https://doi.org/10.1093/ser/mww002.

R Core Team. (2017). R: a language and environment for statistical computing. Vienna, Austria: R Foundation for Statistical Computing URL: https:/www.R-project.org/. Accessed 04 Apr 2018.

Rosenthal, L., \& Levy, S. R. (2012). The relation between polyculturalism and intergroup attitudes among racially and ethnically diverse adults. Cultural Diversity and Ethnic Minority Psychology, 18, 1-16. https://doi.org/10.1037/a0026490.

Rosseel, Y. (2012). lavaan: an $R$ package for structural equation modeling. Journal of Statistical Software, 48, 1-36. https://doi.org/10.18637/jss.v048.i02.

Satherley, N., \& Sibley, C. G. (2016). A dual process model of attitudes toward immigration: predicting intergroup and international relations with China. International Journal of Intercultural Relations, 53, 7282. https://doi.org/10.1016/j.ijintrel.2016.05.008.

Schalk-Soekar, S. R. G., \& van de Vijver, F. J. R. (2008). The concept of multiculturalism: a study among Dutch majority members. Journal of Applied Social Psychology, 38, 2152-2178. https://doi.org/10.1111 j.1559-1816.2008.00385.x.

Scheve, K. F., \& Slaughter, M. J. (2001). Labor market competition and individual preferences over immigration policy. The Review of Economics and Statistics, 83, 133-145. https://doi.org/10.1162 /003465301750160108.

semTools Contributors. (2016). semTools: useful tools for structural equation modeling. R package version 0.4-14. Retrived from http://cran.r-project.org/web/packages/semTools/index.html. Accessed 04 Apr 2018.

Sibley, C. G., Duckitt, J., Bergh, R., Osborne, D., Perry, R., Asbrock, F., Robertson, A., Armstrong, G., Wilson, M. S., \& Barlow, F. K. (2013). A dual process model of attitudes towards immigration: person $\times$ residential area effects in a national sample. Political Psychology, 34, 553-572. https://doi.org/10.1111 /pops.12009.

Sidanius, J., \& Pratto, F. (2001). Social dominance: an intergroup theory of social hierarchy and oppression. Cambridge, UK: Cambridge University Press. https://doi.org/10.1017/cbo9781139175043.

Simon, R. J., \& Sikich, K. W. (2007). Public attitudes toward immigrants and immigration policies across seven nations. International Migration Review, 41, 956-962. https://doi.org/10.1111/j.17477379.2007.00107.x.

Sinn, J. S., \& Hayes, M. W. (2017). Replacing the moral foundations: an evolutionary-coalitional theory of liberal-conservative differences. Political Psychology, 38, 1043-1064. https://doi.org/10.1111 /pops.12361.

Sinn, J. S., \& Hayes, M. W. (2018). Is political conservatism adaptive? Reinterpreting right-wing authoritarianism and social dominance orientation as evolved, sociofunctional strategies. Political Psychology, 39, 1123-1139. https://doi.org/10.1111/pops. 12475.

Šram, Z., \& Dulić, J. (2015). National threat perception, dominance-submissive authoritarian syndrome and totalitarian socialist ideology. The International Journal of Humanities and Social Science, 5, 37-51. 
Stellmacher, J., \& Petzel, T. (2005). Authoritarianism as a group phenomenon. Political Psychology, 26, 245 274. https://doi.org/10.1111/j.1467-9221.2005.00417.x.

Thomsen, L., Green, E. G. T., \& Sidanius, J. (2008). We will hunt them down: how social dominance orientation and right-wing authoritarianism fuel ethnic persecution of immigrants in fundamentally different ways. Journal of Experimental Social Psychology, 44, 1455-1464. https://oi.org/10.1016/j. jesp.2008.06.011.

van de Vliert, E. (2011). Climato-economic origins of variation in ingroup favoritism. Journal of CrossCultural Psychology, 42, 494-515. https://doi.org/10.1177/0022022110381120.

Vorauer, J. D., \& Sasaki, S. J. (2011). In the worst rather than the best of times: effects of salient intergroup ideology in threatening intergroup interactions. Journal of Personality and Social Psychology, 101, 307320. https://doi.org/10.1037/a0023152.

Ward, C., \& Masgoret, A.-M. (2006). An integrative model of attitudes toward immigrants. International Journal of Intercultural Relations, 30, 671-682. https://doi.org/10.1016/j.ijintrel.2006.06.002.

Ward, C., Szabo, A., \& Stuart, J. (2017). Prejudice against immigrants in multicultural societies. In C. G. Sibley \& F. K. Barlow (Eds.), The Cambridge handbook of the psychology of prejudice (pp. 413-437). Cambridge, UK: Cambridge University Press. https://doi.org/10.1017/9781316161579.018.

Welzel, C. (2013). Freedom rising: human empowerment and the quest for emancipation. Cambridge, UK: Cambridge University Press.

Williams, D. R., \& Mohammed, S. A. (2009). Discrimination and racial disparities in health: evidence and needed research. Journal of Behavioral Medicine, 32, 20-47. https://doi.org/10.1007/s10865-008-9185-0.

Publisher's Note Springer Nature remains neutral with regard to jurisdictional claims in published maps and institutional affiliations.

\section{Affiliations}

\section{Dmitry Grigoryev $^{1}$ - Anastasia Batkhina ${ }^{1} \cdot$ Fons van de Vijver ${ }^{1,2,3,4}$. John W. Berry $^{1,5}$}

1 National Research University Higher School of Economics, Moscow, Russia

2 Tilburg University, Tilburg, The Netherlands

3 University of Queensland, Brisbane, Australia

4 North-West University, Potchefstroom, South Africa

5 Queen's University, Kingston, Canada 